\title{
EFFECT OF ERGOTAMINE ON THE VASODEPRESSOR ACTION OF ISOPROPYL-ARTERENOL
}

\author{
TOHORU YUI AND YUJI TAKEO \\ Research Laboratories, Takeda Pharmaceutical Ind., Higashi-Yodogawa, Osaka \\ Received for publication June 24, 1957
}

Isopropyl-arterenol (Isoprenaline or Isuprel, hereafter referred to as Iso) differs from other sympathomimetic amine in having a strong vasodilator action, though it accelerates cardiac activity and relaxes bronchial muscle as much as the other amines do. According to Ahlquist (1948) (1), it is one of the most potent amines to $\beta$-receptor of the plain muscle, with which the amines combine themselves producing the inhibitory responses.

There have been many descriptions that the vasodepressor action of Iso is reversed to vasopressor action by various agents (Hazard et al., 1947 (2), King, 1948 (3), 1949, Fromherz, 1946 (4), Konzett, 1948 (5), Woodbury et al., 1950 (6):. It is of great interest that ergotamine or ergotoxine reverses the vasopressor action of epinephrine (hereafter referred to as Epi) in a large dose and, on the contrary, they reverse the vasodepressor action of Iso to vasopressor action in a small dose. These phenomena have suggested a clue to solve the interaction between the sympathomimetic amines and their receptive mechanism.

Lands et al. (1950) (7) reported that in the pentobarbitalized dog, the Iso-reversal by ergotamine is associated with a marked increase in the amplitude of ventricular contraction, in pulse pressure and in heart rate. In general, barbiturates enhance the pressor action of natural ergot alkaloids [Nickerson, 1949 (8)) and hydrogenated ergot alkaloids [Yui and Takeo, 1957 (9)?. Accordingly, it is presumed that the Iso-reversal induced by ergot alkaloids may be markedly affected by barbiturates used as an anesthetic agent.

This paper proposes to investigate the following questions : the Iso-reversal by ergotamine under the other kind of anesthetics than barbiturate and the effect of ergotamine on the vascular action of Iso in the peripheral vascular beds of an isolated dog's hind leg.

\section{METHODS}

Mongrel dogs weighing 7-14 kg and cats weighing 2.5-3.6 kg were used. Blood pressure responses were observed under the following two kinds of anesthesia: 1) urethane $1.3 \mathrm{~g} / \mathrm{kg}$ intraperitoneally, 2) sodium thiopental $25 \mathrm{mg} / \mathrm{kg}$ intravenously plus sodium barbital 175 $\mathrm{mg} / \mathrm{kg}$ intraperitoneally. Blood pressure was registered on a smoked paper through mercury manometer from a canulated femoral or carotid artery.

An isolated dog's hind leg was artificially perfused through a canulated femoral artery by means of a perfusion pump of Dale-Schuster type (1928) (10) with heparinized whole blood that had been collected from the dog anesthetized with sodium thiopental and sodium 


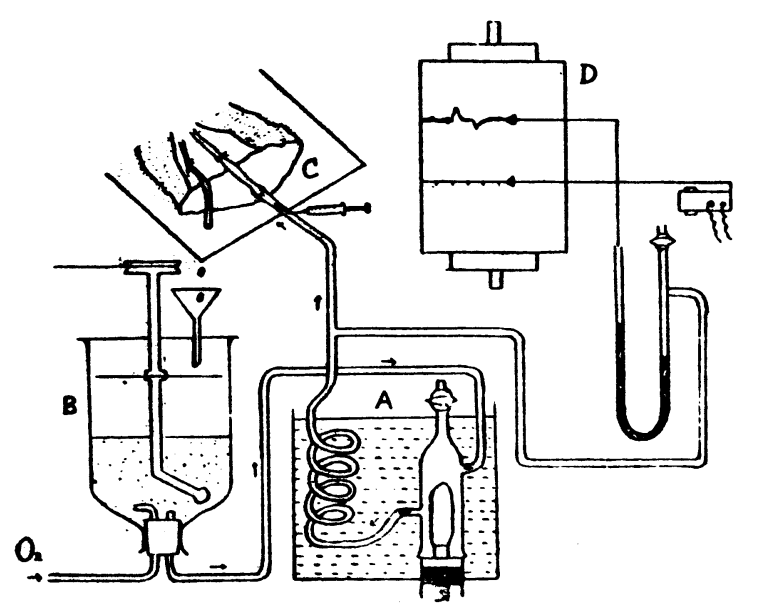

Fig. 1. Diagram of perfusion circuit.
A : perfusion pump
B : artifitial oxygenator
C : isolated dog's hind leg
D : smoked drum

barbital prior to isolation of a leg. Perfusion was performed at constant rate and pulse pressure, and peripheral resistance was recorded on a smoked paper utilizing side pressure of the perfusion tube. Drugs were injected into the inserted canule.

\section{RESULTS}

Effect of ergotamine on blood pressure action of Iso and Epi under two kinds of anesthesia

In urethanized cats, ergotamine intravenously in doses of 0.05-0.1 $\mathrm{mg} / \mathrm{kg}$, lepressed or reversed the vasopressor action of Epi (2-5 $\mu \mathrm{g} / \mathrm{kg})$ without remarkable effects on the

vasodepressor action of Iso $(1 \mu \mathrm{g} / \mathrm{kg})$. After bilateral section of vagus nerves, these responses were still observed.

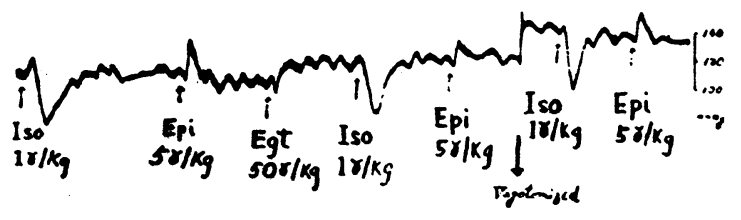

FIG. 2. The responses of Epi and Iso under urethane anesthesia. The response of Epi was slightly depressed but that of Iso was not affected by ergotamine before and after vagotomy. (cat $3.0 \mathrm{~kg}$ \&) Egt : ergotamine tartrate

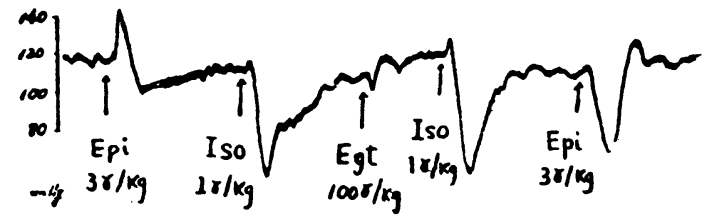

FIG. 3. The response of Epi and Iso under urethane anesthesia. The response of Epi was reversed after ergotamine but that of Iso was not affected. (cat $3.6 \mathrm{~kg}$ \&)
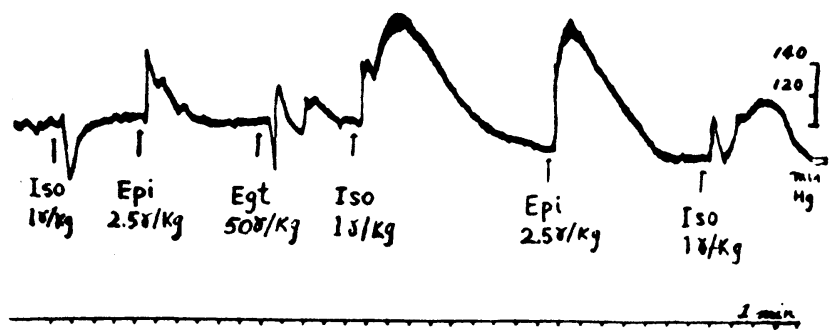

FIG. 4. The responses of Epi and Iso under thiopental-barbital anesthesia. The response of Epi was markedly potentiated by ergotamine and that of Iso was reversed to a complete rise and then became to show a diphasic pattern. (cat $2.7 \mathrm{~kg}$ \&) 
On the other hand, in thiopental-barbitalized cats, ergotamine potentiated the vasopressor action of Epi and reversed the vasodepressor action of Iso to a remarkable vasopressor action. After ergotamine, at first the pattern of the reversal was monophasic and then became diphasic gradually; an abrupt rise $\rightarrow$ a fall $\rightarrow$ a persistent rise.

Effect of ergotamine on peripheral vascular action of Iso and Epi

Although the vasocontrictor action of Epi was shown to be at first depressed to some extent and then reversed to the vasodilator action by addition of ergotamine, however, the vasodilator action of Iso was by no means interferred by the alkaloid.

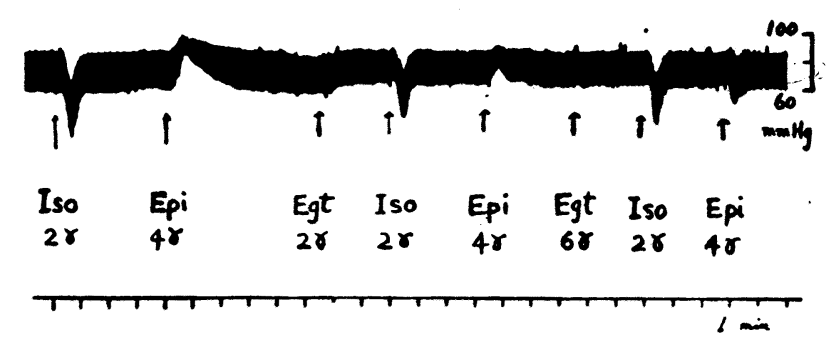

FIG. 5. The responses of Epi and Iso on the vascular beds of isolated dog's hind leg. The response of Epi was depressed and finally reversed by ergotamine but that of Iso was not affected. $(\operatorname{dog} 13 \mathrm{~kg} \hat{\delta}$, right hind leg)

\section{DISCUSSION}

Green (1954) (11) described that ergot alkaloids have complex effects on actions of sympathomimetic amines. They are not only potent inhibitors to the excitatory action of the amines ( $\alpha$-receptor), but also relatively more effectively than the other adrenergic blocking agents in blocking the inhibitory action ( $\beta$-receptor). Ergotamine in a small dose potentiates the pressor action of Epi, whereas it in a large dose depresses or reverses it. The former effect may explain the apparently enhanced sympathomimetic pressor responses induced by ergot alkaloids under barbiturate anesthesia. The present authors (1957) reported that dihydroergokryptine caused a transient rise of blood pressure of cats under thiopentalbarbital anesthesia, while it did a prolonged fall of blood pressure under morphine-urethane anesthesia. This might be due to the potentiation of the barbiturates to the peripheral action of the alkaloid.

It is clear that barbiturates play a role in the Iso-reversal by ergotamine, as judged by the fact that the reversal has been shown to be absent in animals under urethane anesthesia. Therefore, barbiturates seem to be activating agents of ergotamine in producing Iso-reversal.

Though Iso has a strong vasodilator action, its pharmacological actions cannot be regarded as a complete antipode of Epi. This is limited in vascular action. It may well be that the Iso-reversal by ergotamine is originated in the cardiac acceleration of Iso enhanced by ergotamine, as reported by Lands et al.. Ergotamine does not modify the action of Iso on the peripheral vascular beds of an isolated dog's hind leg but depresses or reverses that of Epi. Therefore, there is a definite difference between Epi-reversal and Iso-reversal, because 
the former is associated with peripheral vascular beds but the latter is independent upon them.

\section{SUMMARY}

It has been observed that the vasodepressor action of Iso was reversed to vasopression by ergotamine in cats under thiopental-barbital anesthesia, but no reversal was found under urethane anesthesia, in spite of the finding that the pressor action of Epi was depressed or reversed. Consequently, barbiturates seem to be activating agents in producing the Isoreversal.

When an isolated dog's hind leg was perfused artificially with the heparinized whole blood, the vasodilator action of Iso could not be modified by ergotamine. Therefore, factors responsible for the reversal cannot be found in peripheral vascular beds.

Acknowledgement: The authors wish to express their gratitude to Professor H. Kumagai, Department of Pharmacology, Faculty of Medicine, University of Tokyo, for his active help during the course of the investigation.

\section{REFERENCES}

1) AHLQUIST, R.P.: Amer. J. Physiol. 159, 586 (1948)

2) HAZARD, R. et al.: C. R. Soc. Biol. 141, 594 (1947)

3) King, T.O.: Fed. Proc. 6, 345 (1947) ; 7, 233 (1948)

4) Fromherz, K.: Experimentia 2, 146 (1946)

5) KONZETT, H.: Ibid. 4, 403 (1948)

6) WOODBURY, R.A. et al.: J. Pharmacol. 98, 32 (1950)

7) LANDS, A.M. et al.: Ibid. 100, 248 (1950)

8) Nickerson, M.: Ibid. 95, No. 4, Part 2, 27 (1949)

9) YUI; T. \& TAKEO, Y.: Jap.J. Pharmacol. 7, 55 (1957)

10) DALE, H.H. \& SChUSTER, E.H.S.: J. Physiol. 64, 357 (1928)

11) GREeN, H.D.: DRILL, V.A.: Pharmacology in Medicine 28/3 (1954) 